\title{
25 Research Suare \\ Relationship of serum VITD3, HSCRP and HbA1c level in non diabetic patients referring to tertiary hospital
}

ali zare-mirzaie

Tehran University of Medical Sciences

somayeh mehdizadeh

iran university of medical sciences

pegah babaheidarian ( $\sim$ pegibh@gmail.com )

iran university of medical sciences

\section{Research}

Keywords: VITD3, HSCRP, HbA1c, diabetes

Posted Date: August 19th, 2020

DOI: https://doi.org/10.21203/rs.3.rs-41499/v1

License: (c) (1) This work is licensed under a Creative Commons Attribution 4.0 International License.

Read Full License 


\section{Abstract}

Background: In diabetic patients high HbA1c is associated with high level of HSCRP and VITD3 deficiency could result in diabetes and high $\mathrm{HbA1c}$ level. The aim of this study was to determine the relation of HbA1c, HSCRP and vitamin D3 in healthy individuals who referred to Rasool Akram Hospital.

Methods: In this cross sectional study, individuals who referred to our center between 2018 and 2019 for the measurement of $\mathrm{HbA} 1 \mathrm{c}$ were classified to three groups based on the level of the HbA1c: $<5,5-5.6$ and $5.7 \leq$. Then the Serum level of HSCRP and vitamin D3 were measured and compared between these three groups.

Results: In this study, 90 healthy individuals were studied. In subjects with BMI below 25, no significant difference in HSCRP level was seen in group with low and normal $\mathrm{HbA1c}$, but group with high $\mathrm{HbA1c}$ has non-significant higher level of HSCRP rather than group with normal HbA1c. In subject with BMI higher than 25, group with high $\mathrm{HbA} 1 \mathrm{c}$ and low $\mathrm{HbA} 1 \mathrm{c}$ had non-significant higher level of HSCRP than group with normal $\mathrm{HbA} 1 \mathrm{c}$ and in the subjects, no significance difference at serum level of vitamin D3 level has been identified between $\mathrm{HbA1c}$ groups.

Conclusion: As immunomedulatory role of VitD3 is shown in many studies and low VitD3 could predispose people to diabetes independent of obesity, Conflicting results in various studies emerge an idea to mind that considering relation of other factors responsible in glucose metabolism such as insulin level, IGF-1, C-Peptide and VitD3 could be a better overview on vitD3 effect on glucose metabolism

\section{Introduction}

Association between VITD3 deficiency and diabetes has been well recognized. In the number of studies VITD3 level is much lower in diabetic patients than healthy ones. VITD3 has an immunomedulatory effect. It plays its role in different ways with regulation of cytokine production such as IL-6, CRP and also via insulin secretion and sensitivity. It has been shown that death of islet cell can be prevented by VITD3 (1).

$\mathrm{HbA} 1 \mathrm{c}$ is a valuable biomarker for detecting high risk group for cardiovascular disease even if the patient has no diabetes. Goto et al had reported both low and high level of HbA1c is related with increased risk of cardiovascular disease (2), on the other hand, high level of HSCRP which is an acute phase reactant protein and its level depends on inflammatory systemic response, is reported in diabetic patients with cardiovascular complications(3).

VITD3 deficiency is linked to diabetes and cardiovascular disease and besides obesity it could itself alter the glucose metabolism. Alemzade et al showed that low level of VITD3 in children could result in high insulin resistance and high level of $\mathrm{HbA} 1 \mathrm{c}(4)$.Ordooie et al demonstrated that VITD3 supplement therapy could lower the HbA1c level in diabetic patients(5). The present study is designed to investigate whether 
there is any correlation between VITD level, HSCRP and HbA1c in healthy individuals, which to the best of our knowledge has not been conducted till now.

\section{Methods \& Materials}

\section{Study design and participants}

This is an analytical cross- sectional study on patients being referred to central laboratory lab in a tertiary hospital in Tehran during 2018-2019.The patient anthropometric data was recorded using an individual questionnaire filled by each patient. The exclusion criteria were chronic kidney disease, thyroid disease, and liver failure, Consuming lowering lipid level drugs, anticonvulsive drugs, and VITD3 supplement. Each pregnant or breast feeding woman, alcohol or cigarette consumption, any blood donation since 6 months ago was excluded. Written consent form was taken from the patient. After recording data and calculating $\mathrm{BMI}, \mathrm{HbA} 1 \mathrm{c}, \mathrm{VID} 3$ and HSCRP was measured on each blood sample.

HbA1c was measured by immunoturbidometric assay using BT3000 machine. VID3 (euroimmune kit) and HSCRP (monobind) were measured by ELISA method according to principle protocol.

$\mathrm{HbA1c}$ more than 6.5 were excluded from data and value less than 6.5 was categorized into 3 groups: 1 ) prediabetic Level; 5.7-6.4 2) Normal: 5-5.7 3) low level: less than 5.

VITD3 values are categorized into 4 groups: 1) Normal: more than 50ng/ml 2) Mild deficiency: 25$49.9 \mathrm{ng} / \mathrm{ml} 3$ ) Moderate deficiency: $12.5-24.9 \mathrm{ng} / \mathrm{ml}$ 4) Severe deficiency: less than $12.5 \mathrm{ng} / \mathrm{ml}$.

BMI also is set as four groups: 1) low weight: $B M I<18$ 2) Normal: 18-24.9 3) overweight: 25-29.9 4) obese $>30$

\section{Statistical analysis}

Collected data was analyzed using SPSS version 20(Chicago, Illinois's, USA). For describing quantitative variable, mean and standard deviation was used. For comparing different variable, chi square, ANOVA and post hoc test were used. 0.05 was set as significant level for statistical analysis.

\section{Results}

The study selected 90 healthy volunteer individuals in which 59 were female and 31 were male. Table 1 presents demographic and laboratory data.

For better calculating correlation, the patients were categorized based on BMI, into two groups: less and more than 25 .

\section{In group with BMI less than 25:}


HSCRP mean in HbA1c low, normal and high was $1.1 \mathrm{mg} / \mathrm{l}, 1.4 \mathrm{mg} / \mathrm{l}$ and $2.6 \mathrm{mg} / \mathrm{l}$ with no significant difference $(p$-value $>0.05)$.

VItD3 mean in HbA1c low, normal and high level was $16.2 \mathrm{ng} / \mathrm{ml}, 16.2 \mathrm{ng} / \mathrm{ml}$ and $27.3 \mathrm{ng} / \mathrm{ml}$ which also had no significant difference ( $p$-value>0.05)

\section{In group with BMI more than 25:}

HSCRP in 3 different HbA1c groups follow $U$ shape curve. (Figure 1). People with higher HbA1c had higher HSCRP in comparison to normal HbA1c which also had no significant difference ( $p$-value $>0.05)$ and there is also the same result for VIT D3 in 3 different HbA1c group. ( $p$-Value $>0.05$ )

In women, HSCRP mean level between HbA1c low $(2.5 \mathrm{mg} / \mathrm{l})$ and normal $(2.5 \mathrm{mg} / \mathrm{l})$ level was not statistically significant ( $\mathrm{p}$-value $>0.05$ ) whereas in high level HbA1c group was $3.0 \mathrm{mg} / \mathrm{l}$ which is higher than other group but with no significant difference $(p$-value $>0.05)$. There is also the same result for each group for men, no significant difference in VITD3 and HSCRP between different HbA1C groups.

\section{HSCRP level in different VITD3 groups adjusted to BMI and sex}

Mean HSCRP level in severe deficiency VitD3 was $2.7 \mathrm{mg} / \mathrm{l}$, in moderate deficiency VitD3 $1.8 \mathrm{mg} / \mathrm{l}$, in mild deficiency $1.7 \mathrm{mg} / \mathrm{l}$ and in normal group was $3.1 \mathrm{mg} / \mathrm{I}$ which after post hoc analysis there was no significant difference $(p$-value $>0.05)$

\section{HSCRP and VITD3 in different HbA1c group according to Age}

In different age groups, there is no significance difference between hscrp in different levels. After categorizing patients age into less and more than 60 years. There is also no significant difference ( $p$ value $>0.05)$

\section{Discussion}

The current study showed that in both volunteer groups with BMI more and less than 25, people with high $\mathrm{HbA1c}$ in compare to normal HbA1c, have higher HSCRP level and in group with BMI more than 25 and low HbA1C, HSCRP were higher, However it was not statistically significant .In our study, no relation has been found between VITD3 level and different HbA1c groups.

An inverse relation between VITD3 and HSCRP was found in people younger than 60 years which is in contrast to people older than 60 years. 
In people with BMI less than 25, in compare to people with normal HbA1c, people with high $\mathrm{HbA} 1 \mathrm{C}$ level have higher HSCRP level which shows increase of this acute phase reactant in higher HbA1c level. As injury induced by mild systemic inflammation has an important role in pathogenesis of diabetes (6), HSCRP role in predicting diabetes in healthy individuals which can be deposited in atherosclerotic lesion and result in rupture of plaques $(7,8)$. In the other hand, metabolic glucose products could lead to activation of macrophages, higher oxidative stress and production of IL- 6 and HSCRP (9) .King et al showed that higher HbA1c has an association with higher HSCRP (10). Sahn et al demonstrated that decrease in HbA1c level could result in decrease of HSCRP level (11).Shnell et al showed that postprandial glucose effect on HSCRP level more than HbA1c alone(12). Sarinnapakorn et al showed that high HbA1c was associated with high HSCRP in obese diabetic women. (13). In our study, people with BMI more than 25 have different HSCRP pattern in compare to groups with BMI less than 25.In this group, along with higher HSCRP in high HbA1c level, people with low HbA1c has also high HSCRP which leads to $U$ shape curve that is not demonstrated yet in latter studies.

Selvin et al (14) showed low level of glucose and HbA1c could result in more ischemic heart attacks which the mechanism is not yet truly understood. We believed that like cholesterol, $U$ shape curve of HbA1c could be a potential health risk for humans.

Gotto et al have showed increased risk of cardiovascular disease in patients with low and high level of HbA1c which supporting our findings (2). Although there is no statistically difference, but different population sampling in our study, healthy individuals in contrast to diabetic patients in most of latter studies $(15,16)$ could justify this finding and there may be also an interfering factor besides $\mathrm{HbA} 1 \mathrm{c}$ level which is not investigated in our study.

Our study showed that people with high BMI and severe VIT D3 deficiency have higher HSCRP than other group when adjusted with age, in people younger than 60 year old; decrease in VITD3 level accompanied by high HSCRP whereas in people older than 60 year, this relation is reverse. Data from latter studies (17, $18,19)$ are very conflicting,

This finding may be due to some other interfering factor such as inflammatory markers. Difference between results of our study and others may be due to different study population.

Our study showed no relation between HbA1c and VITD3 in similar to Haidari et al (20) which demonstrated no relation between HbA1C and VITD3 in non obese diabetic patients in contrast to findings of Salehpoor et al (21) in diabetic patient.

\section{Conclusion}

As immunomedulatory role of VITD3 is shown in many studies and low VITD3 could predispose people to diabetes independent of obesity, Conflicting results in various studies emerge an idea to mind that 
considering relation of other factors responsible in glucose metabolism such as insulin level, IGF-1, CPeptide and VITD3 could be a better overview on vitD3 effect on glucose metabolism and its effect on HSCRP level.

\section{Declarations}

\section{The availability of data and materials}

The data is available from corresponding author for reasonable questions

\section{Acknowledgment}

We wish to thank you the technician team of Rasoul akram hospital

\section{Funding}

Not applicable

\section{Author information}

\section{Affiliation}

Department of pathology, Rasoul akram hospital, Iran University of medical sciences. Tehran, Iran

\section{Author contribution}

Ali zare- mirzaie conducted and conceptualized the study, somayeh mehdizadeh gathering data and analyzed data, pegah babaheidarian wrote the manuscript and finalized it.

\section{Corresponding author}

Correspondence to Pegah Babaheidarian

\section{Ethical declaration}

\section{Ethical approval and consent to participate}

The current study was approved by Iran university of medical sciences, ethical committee, written consent form was taken from participants

\section{Consent for publication}

There is a consent form for publication of data

\section{Competing interest}




\section{References}

1. International Expert Committee, "International Expert Committee report on the role of the A1C assay in the diagnosis of diabetes," Diabetes Care, vol. 32, no. 7, pp. 1327-1334, 2009.

2. Goto A, Noda M, Matsushita Y, Goto M, Kato M, Isogawa A, Takahashi Y, Kurotani K, Oba S, Nanri A, Mizoue T, Yamagishi K, Yatsuya H, Saito I, Kokubo Y, Sawada N, Inoue M, Iso H, Kadowaki T, Tsugane S; JPHC Study Group.Hemoglobin a1c levels and the risk of cardiovascular disease in people without known diabetes: a population-based cohort study in Japan.Medicine (Baltimore). 2015;94(17):e785.

3. Aggarwal V, Schneider AL, Selvin E. Low hemoglobin A1c in nondiabetic adults: an elevated risk state? Diabetes Care. 2012;35:2055-2060.

4. Alemzadeh R1, Kichler J, Babar G, Calhoun M. Hypovitaminosis D in obese children and adolescents: relationship with adiposity, insulin sensitivity, ethnicity, and season. Metabolism. 2008;57(2):183-91.

5. Ordooei M1, Shojaoddiny-Ardekani A, Hoseinipoor SH, Soleimanizad R, Miroliai M, Zare-Zardini H. Effect of vitamin d on hba1c levels of children and adolescents with diabetes mellitus type 1. Minerva Pediatr. 2014; 20.

6. de Carvalho Vidigal F1, Guedes Cocate P, Gonçalves Pereira L, de Cássia Gonçalves Alfenas R. The role of hyperglycemia in the induction of oxidative stress and inflammatory process. Nutr Hosp. 2012;27(5):1391-8.

7. Associations among. Shi CH, Wang C, Bai R, Zhang XY, Men LL, DU JL7- glycemic excursions, glycated hemoglobin and high-sensitivity C-reactive protein in patients with poorly controlled type 2 diabetes mellitus. Exp Ther Med. 2015; 10(5):1937-1942.

8. Earl S. Ford, Guixiang Zhao, James Tsai, Chaoyang Li. Associations Between Concentrations of Vitamin D and Concentrations of Insulin, Glucose, and HbA1c Among Adolescents in the United States.Diabetes Care. 2011; 34(3): 646-648.

9. Kostoglou-Athanassiou I, Athanassiou P, Gkountouvas A, Kaldrymides P. Vitamin D and glycemic control in diabetes mellitus type 2.Ther Adv Endocrinol Metab. 2013;4(4):122-8.

10. King DE, Mainous AG , Buchanan TA, Pearson WS. C-reactive protein and glycemic control in adults with diabetes. Diabetes Care 2003; 26:1535-1539

11. markers (high sensitivity $C$ reactive protein, nuclear Misra DP, Das S, Sahu PK11-factor KB and adiponectin) in Indian patients with type 2 diabetes mellitus with and without macrovascular complications. Metab Syndr Relat Disord 10: 209 213, 2012. 
12. Schnell O, Amann-Zalan I, Jelsovsky Z, Moritz A, Bermejo JL, Parkin CG, Schweitzer MA, Fisher L, Polonsky WH. Changes in A1C levels are significantly associated with changes in levels of the cardiovascular risk biomarker hs-CRP: results from the SteP study Diabetes Care. 2013;36(7):2084-9.

13. Tutuncu Y, Satman I, Celik S, Dinccag N, Karsidag K, Telci A, Genc S, Issever H, Tuomilehto J, Omer B. A Comparison of hs-CRP Levels in New Diabetes Groups Diagnosed Based on FPG, 2-hPG, or HbA1c Criteria.J Diabetes Res. 2016; 2016:5827041.

14. Selvin E, Steffes MW, Zhu H, et al. Glycated hemoglobin, diabetes, and cardiovascular risk in nondiabetic adults. N Engl J Med. 2010;362:800-811

15. Selvin E, Coresh J, Shahar E, Zhang L, Steffes M, Sharrett AR. Glycaemia (haemoglobin A1c) and incident ischaemic stroke: the Atherosclerosis Risk in Communities (ARIC) Study. Lancet Neurol. 2005;4:821-6.

16. Yazdchi R, Gargari BP, Asghari-Jafarabadi M, Sahhaf F. Effects of vitamin D3 supplementation on metabolic indices and hs-CRP levels in gestational diabetes mellitus patients: a randomized, doubleblinded, placebo-controlled clinical trial. Nutr Res Pract. 2016;10(3):328-35.

17. Sadiya A, Ahmed SM, Carlsson M, Tesfa Y, George M, Ali SH, Siddieg HH, Abusnana S. Vitamin D3 supplementation in obese type 2 diabetes subjects in Ajman, UAE: a randomized controlled doubleblinded clinical trial. Eur J Clin Nutr. 2015;69:707-711

18. Delvin EE, Lambert M, Levy E, et al. Vitamin D3 status is modestly associated with glycemia and indicators of lipid metabolism in French-Canadian children and adolescents. J Nutr 2010;140:987991

19. Zare-Mirzaie A, Kazeminezhad B, Akbari Ghouchani M. The Correlation Between Serum Vitamin D Level and Total Antioxidant Capacity in Diabetic and Non-diabetic Subjects in Iran. Iran J Pathol. 2018;13(2):212-219.

20. Haidari F, Zakerkish M, Karandish M, Saki A, Pooraziz S.Association between Serum Vitamin D Level and Glycemic and Inflammatory Markers in Non-obese Patients with Type 2 Diabetes. Iran J Med Sci. 2016;41(5):367-73.

21. Salehpour A, Shidfar F, Hosseinpanah F, Vafa M, Razaghi M, Amiri F. Does vitamin D33 supplementation improve glucose homeostasis in overweight or obese women? A double-blind, randomized, placebo-controlled clinical trial. Diabet Med. 2013;30:1477-81.

\section{Table 1}




\begin{tabular}{|c|c|c|}
\hline & & Healthy subjects \\
\hline Subjects no. & & 90 \\
\hline Sex(Female) & & $56(65.1)$ \\
\hline Age(years) & & $46(18-79)$ \\
\hline HbA1c (\%) & & $5.3(4.3-6.4)$ \\
\hline \multirow[t]{3}{*}{ HbA1c groups } & $\operatorname{Low}(\leq 5)$ & $32(35)$ \\
\hline & (5-5.7)Normal & $33(37)$ \\
\hline & $\operatorname{High}(5.7<)$ & 25(28) \\
\hline hsCRP ( mg/L) & & $(0.09-11.6) 2.2$ \\
\hline Vitamin D3 (ng/ml) & & 18.1(1-91) \\
\hline \multirow[t]{4}{*}{ Vitamin D3 groups } & $(50 \leq)$ Normal & $4(4.7)$ \\
\hline & mild (25-49.9) & (11.6)11 \\
\hline & Moderate(12.5-24.9) & $(41.9) 53$ \\
\hline & Severe $(\leq 12.4)$ & $(41.9) 40$ \\
\hline $\mathrm{BMI}(\mathrm{Kg} / \mathrm{m} 2)$ & & $26.9(15.5-43)$ \\
\hline \multirow[t]{4}{*}{ BMI groups } & Underweight( $\leq 18.5)$ & $5(5.8)$ \\
\hline & (18.5-24.9) Normal & $25(24.4)$ \\
\hline & Overweight(25-29.9) & (36)33 \\
\hline & Obese $(30 \leq)$ & (29.9)19 \\
\hline
\end{tabular}

Table1.Demographic and laboratory data of selected patients

Figures 


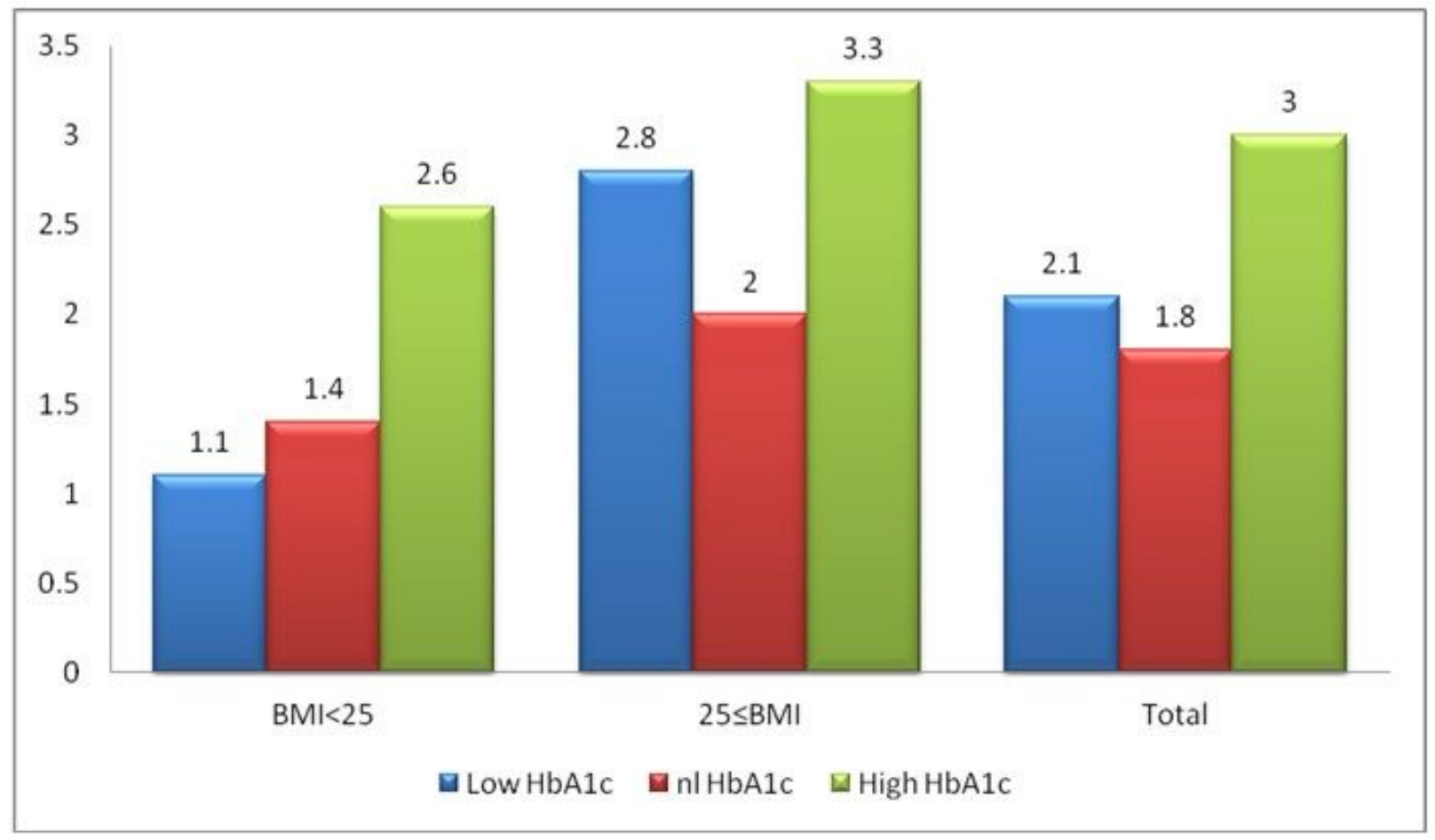

Figure 1

Mean Hscrp level in different HbA1c levels according to BMI 


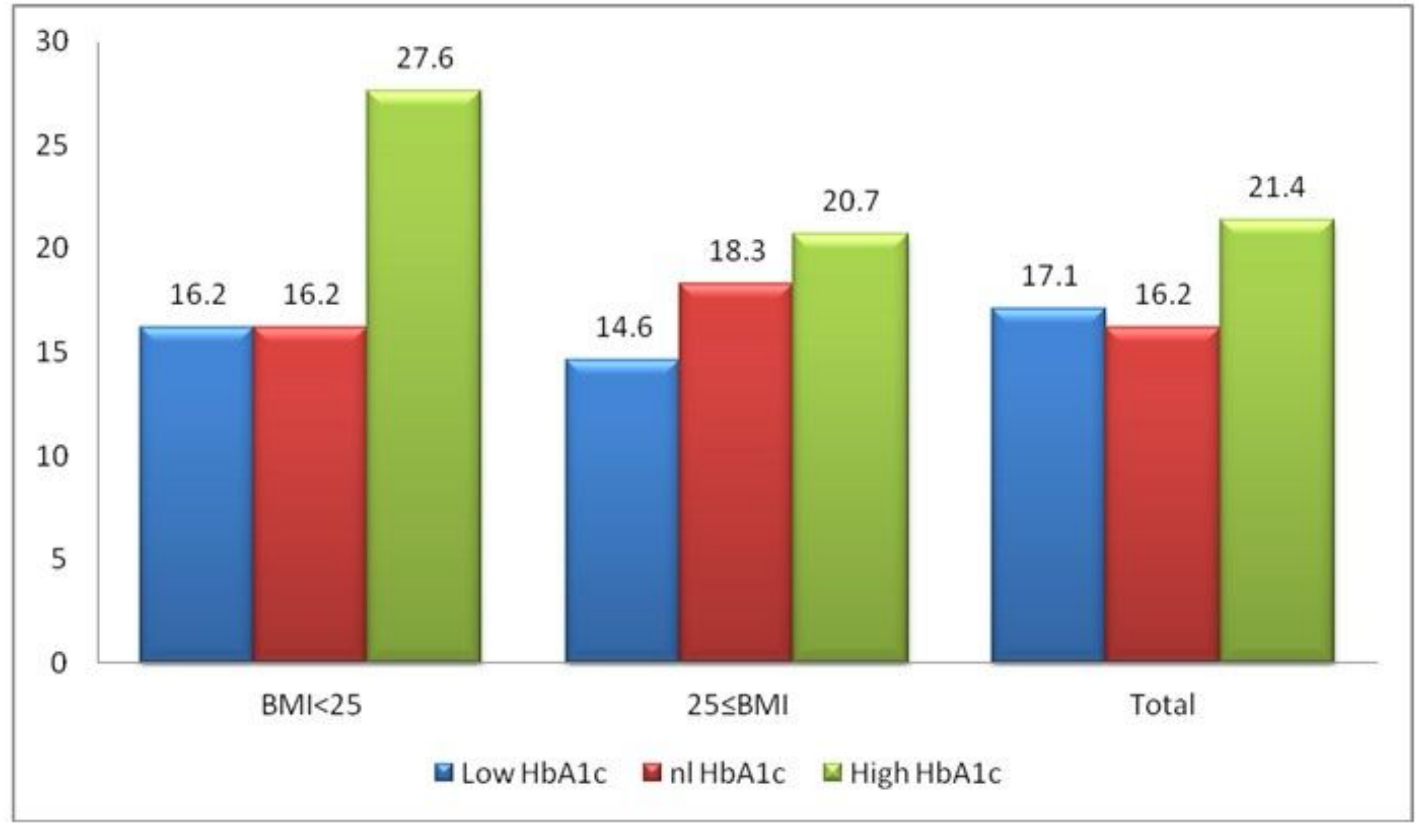

Figure 2

Mean VITD3 level in different HbA1c according to BMI 